Vol. 12 (1): 29-40 (2022)

\title{
REGENERATION EFFICIENCY ASSESSMENT OF A UMO TREATED WITH ACTIVATED KARAQEVA'S KOSOVO BENTONITE
}

\author{
Arjan Korpa $^{1 *}$, Sara Dervishi ${ }^{1}$, Diana Gecaj ${ }^{1}$, Kristi Shahu $^{1}$, Spiro Drushku ${ }^{2}$ \\ ${ }^{1 *}$ University of Tirana, Faculty of Natural Sciences, Department of Chemistry, Tirana, Albania; \\ ${ }^{2}$ University of Tirana, Faculty of Natural Sciences, Department of Industrial Chemistry, Tirana, Albania; \\ Corresponding Author Arjan Korpa, e-mail: arjan.korpa@fshn.edu.al;
}

Received October 2021; Accepted November 2021; Published January 2022;

DOI: https://doi.org/10.31407/ijees12.105

\begin{abstract}
The regeneration efficiency of activated Karaqeva's (Kosovo) bentonite was assessed with a used motor oil (UMO) having run about $15000-20000 \mathrm{~km}$. The bentonite was activated with three activation methods: acid, alkaline and combined acid - alkaline activation. The optimal activation conditions of Karaqeva's bentonite with the employed oil and each of the three activation methods was found out. Bentonite samples were characterized using X-ray powder diffraction (XRD), Fourier transform infrared (FTIR), as well as cation exchange capacity (CEC), surface and porosity properties before and after treatment with all three methods. The activated bentonite's oil regeneration efficiency could be predicted using the following key parameters; CEC, Ssp, Vt, Smi and Sext. Karaqeva's bentonite activated by the acid and combined activation method in the totality of the performance shows the best efficiency for the UMO regeneration.
\end{abstract}

Keywords: Karaqeva's (Kosovo) bentonite; acid, alkaline and combined activation; UMO regeneration efficiency. 